\title{
ANÁLISE DA POLÍTICA EDITORIAL DA MÍDIA SANTA-MARIENSE SOBRE A DIVULGAÇÃO DE SUICÍDIOS
}

VALMOR RHODEN

UNIVERSIDADE FEDERAL DO PAMPA CAMPUS SÃO BORJA, RIO GRANDE DO SUL, BRASIL VRHODEN6@GMAIL.COM

JULIANA LIMA MOREIRA RHODEN UNIVERSIDADE FEDERAL DO PAMPA CAMPUS SÃO BORJA, RIO GRANDE DO SUL, BRASIL JULI.RHODEN@GMAIL.COM

DOUGLAS MOREIRA DORNELLES

UNIVERSIDADE FRANCISCANA SANTA MARIA, RIO GRANDE DO SUL, BRASIL

HTTP://DX.DOI.ORG/10.5902/2316882X28626 


\section{ANÁLISE DA POLÍTICA EDITORIAL DA MÍDIA SANTA-MARIENSE SOBRE A DIVULGAÇÃO DE SUICÍDIOS}

Resumo: O objetivo da presente investigação foi verificar a política editorial dos principais veículos de comunicação da imprensa santa-mariense sobre o suicídio. A divulgação de casos de suicídio requer muito conhecimento e responsabilidade para não servir de gatilho para o aumento no número de casos. A metodologia utilizada foi a pesquisa qualitativa de cunho exploratório, entrevista com os responsáveis do setor jornalístico, levantamento documental e bibliográfico.

Palavras-chave: Mídia; Suicídio; fatores de risco.

\section{ANÁLISIS DE LA POLÍTICA EDITORIAL DE LOS MEDIOS DE COMU- NICACIÓN SANTA-MARIANA SOBRE LA DIVULGACIÓN DE SUICI- DIOS}

Resumen: El objetivo de la presente investigación fue verificar la política editorial de los principales medios de comunicación de la prensa santa-mariana sobre el suicidio. La divulgación de casos de suicidio requiere mucho conocimiento y responsabilidad para no servir de gatillo para el aumento en el número de casos. La metodología utilizada fue la investigación cualitativa de cuño exploratorio, entrevista con los responsables del sector periodístico, levantamiento documental y bibliográfico.

Palabras clave: Medios; Suicidio; factores de riesgo.

\section{ANALYSIS OF THE EDITORIAL POLICY OF THE SANTA-MARIENSE MEDIA ON THE DISSEMINATION OF SUICIDES}

Abstract: The objective of the present investigation was to verify the editorial policy of the main communication vehicles of the Santa Maria press about suicide. The disclosure of suicide cases requires a great deal of knowledge and responsibility not to trigger the increase in the number of cases. The methodology used was the qualitative research of an exploratory nature, interviews with journalists, documentary and bibliographical surveys.

Keywords: Media; Suicide; risk factors. 


\section{UM BREVE PANORAMA ATUAL DA MÍdIA NO BRASIL}

As concessões de rádio e TV no Brasil são públicas. As renovações acontecem a cada dez anos para emissoras de rádio e de quinze em quinze para canais de televisão e devem ser feitas junto Ministério das Comunicações. A situação é um pouco diferente para os jornais impressos que não são concessões, são empresas privadas, por mais que hajam Associações de Jornais que tentam reunir questões relacionadas a periodicidade, estrutura administrativa, número de páginas, entre outros.

O levantamento mais recente realizado pela Secretaria de Comunicação Eletrônica do ministério das Comunicações (2014) indica que o Brasil tem 9.771 emissoras, sendo 1.921 AMs; 3.209 FMs (sendo 469 educativas) e 4.641 FMs comunitárias. Entre as TVs comerciais, há 6.197 retransmissoras, 272 geradoras e 39 que transmitem o sinal digital. As emissoras educativas somam 243 estações: 164 rádios e 79 TVs. Já em relação aos jornais, segundo a Associação Nacional de Jornais (ANJ), há 3.076 jornais, incluindo várias periodicidades ( diária, semanal, quinzenal, entre outros), sendo 722 diários (dados de 2013).

Segundo Duarte (2006, p. 02), a Comunicação Pública é um conceito que tem origem na noção de comunicação governamental. $E$ isto é um pouco do que queremos discutir neste trabalho que intercala a comunicação com a psicologia sobre a temática considerada um tabu ainda para muitos, o suicídio.

A metodologia utiliza a pesquisa bibliográfica que dialoga com a comunicação e Psicologia para entender a interface - proposta aqui no trabalho como debate. Além disto, está amparada na pesquisa documental. Dos veículos analisados - apenas dois deles - que fazem parte do mesmo grupo - possuem documento oficial - sobre a política editorial - que engloba a questão central do estudo que é o suicídio. Por isto, utilizamos a entrevista como técnica complementar com os responsáveis dos demais veículos analisados. A entrevista, enviada por e-mail, tinha uma questão que perguntava qual era a política editorial do veículo em relação à divulgação de suicídios em Santa Maria?

Foram analisadas as duas emissoras de TV com produção local, A RBS e TV Pampa, as cinco emissoras AM e o Jornal Diário de Santa Maria. 


\section{A PSICOLOGIA E OS DESAFIOS RELACIONADOS AO SUICÍDIO}

Quando se fala em suicídio automaticamente se remete a um recorte social atrelado ao momento histórico vivido por uma sociedade. A vanguarda, portanto, se fundamenta em uma dinâmica contextual relacionada aos valores éticos e morais vigentes na estrutura sistêmica que rege a instância social dentro da complexidade das relações humanas. Esse atravessamento ideológico na fundamentação técnica da morte voluntária tem alguns marcadores históricos delimitados em função da época, como, por exemplo,na idade média ocidental, em que a influência religiosa e a concentração de poder e terras definia o suicídio muito em relação ao papel social cujo qual o indivíduo cumpria naquela determinada organização, caracterizada pela rigidez de classes, e como isto definia o olhar do outro com relação ao ato de atentar contra a própria vida. A justiça civil e a igreja tinham visões diferentes conforme a classe social do indivíduo que tenha praticado o ato suicida, por exemplo, camponeses e artesãos que viviam em situação de extrema vulnerabilidade eram vistos como pecadores, cujo fato de atentar contra a própria vida estava relacionado com um vício fatal influenciado pelo diabo. Já para membros do clero, o suicídio era visto como um ato heroico, apontando devoção e fé, como se assumisse o papel de mártir, romantizado pela própria igreja, a fim de preservar sua imagem. Para a nobreza, o fato de se suicidar estava relacionado com heroísmo, assim como para os cavaleiros e guerreiros que se deixavam morrer em batalhas para que não fossem escravizados pelos inimigos. Nesse período histórico, igreja e coroa - mantinham alguns interesses comuns, e cada qual defendendo seu ponto de vista chegava a lugares comuns com o intuito acentuar o seu domínio perante o povo.

Porém, ao final da idade média, ocorre a cisão entre a coroa e a igreja em função da reforma protestante, o que faz com que se modifique o paradigma da ótica para o suicídio, que com o avanço da medicina e da sua influência, desloca o suicídio de um fato pecaminoso para um fato patológico.

É um desafio para a Psicologia entender e tratar das causas específicas básicas que levam uma pessoa a se matar. E para a sociedade como um todo - é fundamental fomentar o desenvolvimento de planos de ação adequados ao cenário brasileiro e à saúde pública.

Em 2013, o Conselho Federal de Psicologia lançou uma publicação - re-

Rev.Cad.Comun. Santa Maria, v.22, n.1, art 5, p.106 de 120, jan/abr.2018 
latando os desafios para a área. Segundo o documento, mais de um milhão de pessoas tiram a própria vida todos os anos no mundo. No Brasil, são foram mais de nove mil em 2011. Já os números do serviço de estatística da Polícia Civil do Estado do Rio Grande do Sul, dos últimos três anos, ou seja, de 2014 a 2016 - mostram que foram 3.707 suicídios registrados. Em Santa Maria, de acordo com este mesmo levantamento foram 158 casos, sendo 57 em 2014, 54 em 2015 e 47 em 2016. Ou seja, analisando os dados locais neste triênio houve um decréscimo de cerca de $18 \%$, no período. Comparado com os números totais no período registrados no estado, o município representa $4,2 \%$ do total de suicídios.

Segundo Rigo (2013, p. 31), suicídio é classificado pelo Código Internacional das Doenças, (capítulo XX da CID-10) como morte violenta por causas externas, isto é, morte não decorrente de doença (OMS, $10^{a}$ Revisão, CID-10, 1995). O suicídio é um fenômeno complexo e multifatorial no qual a interação de fatores individuais, sociais e culturais será determinante na decisão de tirar a própria vida.

O Conselho Federal de Psicologia - CFP - (2013, p. 11) afirma a sua responsabilidade, no sentido também de levar a informação, que corrobora com o foco deste artigo.

O CFP, portanto, assume a responsabilidade neste momento de promover este aumento do acesso público e profissional às informações sobre os aspectos de prevenção e comportamentos de suicídio e possibilitar a promoção de serviços de apoio e reabilitação de pessoas afetadas por esse tipo de ocorrência.

Neste sentido, a mídia em parceria com outros setores da sociedade (setores e profissionais da saúde e divulgação de políticas públicas e trabalhos de ONgs, por exemplo), quando trabalham de forma articulada, podem dar resultado interessante para a diminuição de um problema social, como o do suicídio, abordado neste estudo.

Werlang (2013, p. 25) relata um pouco da complexidade que é o suicídio, para a psicologia:

É bastante difícil compreender por que um determinado indivíduo decide cometer suicídio, ao passo que outras pessoas em situação similar não o fazem. O que se pode afirmar, considerando a experiência clínica e a experiência de pesquisa, é que há grande complexidade para compreender o comportamento suicida. Sabemos que há fatores emocionais, psiquiátricos, religio-

Rev.Cad.Comun. Santa Maria, v.22, n.1, art 5, p.107 de 120, jan/abr.2018 
sos e socioculturais. São um conjunto de fatores que ajudam a compreender a situação de vida, o sofrimento que essa pessoa carrega e, por isso, a busca da morte. Até podemos dizer que, por vezes, a pessoa não quer se matar. Quer, antes, eliminar a dor, diminuir o sofrimento e, por isso, busca, de repente, um método que o leva a morte.

São muitos os desafios postos, mas a autora complementa que (2013, p.29):

No âmbito da saúde pública, o psicólogo pode intervir a partir do momento em que possui a qualificação suficiente para entender o fenômeno e identificar fatores que levam ao risco do suicídio. O psicólogo e todos os profissionais que atuam na área da saúde têm disponíveis publicações, de órgãos como o Ministério da Saúde, que auxiliam o profissional a atuar de forma mais adequada.

A autora defende que o trabalho deve ser feito com a família. "A família tem de saber lidar com a morte. Geralmente, esse é um assunto que a família esconde, por acreditar que os filhos pequenos não terão recursos psíquicos para encarar a situação." (WERLANG, 2013, p. 27).

Nos anos 2000, a região sul do Brasil já representava a que tinha os maiores índices de suicídios do país, por isto, segundo Werlang (2013, p.27):

Em 2005, o Ministério da Saúde criou um Grupo de Trabalho (GT) com a finalidade de organizar diretrizes nacionais para trabalhar com o comportamento suicida. Esse GT foi integrado por pesquisadores. Assim, foi possível, em 2006, organizar diretrizes em Porto Alegre, por ser o Rio Grande do Sul o estado que apresenta os maiores índices de suicídio no país. Toda a região Sul, formada por Santa Catarina, Paraná e Rio Grande do Sul, apresenta o maior número de suicídio.

Estes dados apresentados justificam este estudo e a tentativa de contribuir, de forma acadêmica com a problemática social. 


\section{A PESquisa CoM OS Veículos de COMUNICAÇÃo de SANTA MARIA}

Foram analisadas as duas emissoras de TV com produção local, A RBS e TV Pampa. Das emissoras de rádio - foram todas as cinco emissoras AM (Amplitude Modulada) da cidade. O critério de escolha destas é por terem geração de conteúdo e programas jornalísticos em sua programação. Os nomes dos entrevistados dos veículos de comunicação não foram divulgados no trabalho.

Em relação a jornal impresso - apenas o Diário de Santa Maria será analisado, pois é o único com circulação diária da cidade.

Nos veículos que tem regulação escrita sobre esta política editorial, esta foi avaliada, que no estudo foi a RBS TV e o Diário de Santa Maria. Nos demais - os departamentos de jornalismo foram contatados através de email e quando necessário, via telefone, reforçando a importância de responderem por escrito o questionamento do trabalho que é entender a política editorial do veículo sobre a divulgaçãode suicídios.

\subsection{RBS TV}

O grupo RBS, ao qual está vinculada a sucursal de Santa Maria - segue o que está estabelecido no Guia de Ética e Autorregulamentação Jornalística (2011). O documento tem um item que fala especificamente sobre a questão (2011, p. 22):

Atos de suicídio ou de automutilação só devem ser noticiados quando envolverem pessoa pública, caracterizarem o comportamento de determinado segmento social ou tiverem provocado forte impacto na comunidade. Mesmo nestes casos, deve-se evitar detalhar as razões do ato e, sempre que possível, agregar informações de orientação ao público, ouvindo-se especialistas que possam ajudar na prevenção.

Ou seja, a divulgação se restringe a pessoas públicas e devem vir acompanhadas com entrevistas com profissionais para auxiliar na prevenção.

\subsection{TV PAMPA}

Quem nos respondeu inicialmente foi o setor de atendimento ao cliente (SAC) da emissora. Em sua resposta, ressalta que a "TV Pampa, quando

Rev.Cad.Comun. Santa Maria, v.22, n.1, art 5, p.109 de 120, jan/abr.2018 
noticia, mantém a informação estritamente factual, de forma a jamais servir de estimulo para novos casos. Sendo os textos destes fatos, extremamente revisados pela equipe editorial e direção do programa."

O chefe de produção da região central da emissora complementou que "foi a partir de um evento realizado na UFSM, onde participamos junto com outros veículos que passamos a discutir mais sobre o assunto e entender que temos sim que divulgar e tratar mais sobre o tema, como forma de alerta, de prevenção. Começamos também a divulgar mais o número do CVV e fazer entrevistas com profissionais da saúde. Assim tem sido nosso trabaIho no jornalismo, sobre esse assunto. Tudo de forma muito natural e cumprindo nosso compromisso com a comunidade e nossos telespectadores."

\subsection{DIÁRIO DE SANTA MARIA}

O jornal é atualmente o único diário de Santa Maria. Ele esteve vinculado ao Grupo RBS até o mês de janeiro de 2017. Em $1^{\circ}$ de fevereiro um grupo de empresários locais assumiu sua direção.

O jornal esclareceu que, em 2015, várias reportagens especiais foram feitas sobre o tema, justamente para discutir de que forma o assunto precisa ser tratado. "Editorialmente, o jornal não publica casos de suicídio, exceto em casos em que a pessoa envolvida é um ente público, pois, nesse caso, a notícia seria de interesse da sociedade. $O$ outro caso em que noticiamos suicídio é quando o fato ocorre em alguma área de domínio público e tem um contexto que chama a atenção da comunidade. Um exemplo disso foi um suicídio ocorrido há algum tempo, em que a pessoa jogou-se da Garganta do Diabo. Ela tentou, primeiramente, jogar-se com o carro, mas, como não conseguiu, acabou saindo do carro e se atirando de lá. Ocorre que o carro dela quebrou parte do guardrail do viaduto e ficou pendurado, chamando a atenção dos motoristas que passavam pelo local. E, mesmo assim, publicamos a notícia sem darmos muitos detalhes do suicídio, apenas relatando que houve o fato."

\subsection{RÁDIO SANTAMARIENSE}

A emissora faz parte da mesma família detentora do Jornal diário A Razão que encerrou as atividades em fevereiro de 2017, por isto, no momento em que realizamos este trabalho - a emissora estava passando por um processo de reestruturação, mas conseguimos contato com o coor-

Rev.Cad.Comun. Santa Maria, v.22, n.1, art 5, p.110 de 120, jan/abr.2018 
denador de jornalismo da emissora, que esclareceu que a Santamariense não divulga, em princípio, casos de suicídio. Somente quando uma pessoa conhecida, ou que tenha algum cargo importante se suicida, então a rádio noticia. "Há situações em que alguém se joga de um prédio, ou se suicida em um lugar público. Então, do ponto de vista jornalístico, precisa divulgar. Afinal, muita gente viu a pessoa morta e fica ruim para a rádio deixar de noticiar. Sempre acreditei que se deva evitar mencionar o suicídio na imprensa. Acho que pode levar a outros, que tenham tendência a isso, a repetir o gesto."

\subsection{RÁDIO MEDIANEIRA}

O Sistema Medianeira de rádios, composto pelas Rádios Medianeira AM e Medianeira FM, têm como política editorial "não divulgar ocorrências de suicídio, exceto casos que envolvam figuras públicas e que venham a causar algum tipo de comoção social."

\subsection{RÁDIO IMEMBUÍ}

De acordo com o coordenador de jornalismo, a rádio divulga atos de suicídio, somente quando envolvem pessoas públicas ou nas situações que causem impacto na população."Procuramos não entrar em detalhes sobre os motivos que levaram a pessoa a cometer o ato. Ao longo de nossa programação de jornalismo, ouvimos pessoas que atuam nesta temática, no sentido de orientar para prevenir que novos casos aconteçam."

\subsection{RÁDIO GUARATHAN}

Segundo o Coordenador de Jornalismo da emissora, a divulgação informações sobre casos de suicídios acontece somente quando "estão envolvidas pessoa conhecidas (político ou empresário atuante ou até empresário conhecido da população). A divulgação rotineira de suicídios pode incentivar outras pessoas que estão com problemas."

1 Desde junho de 2017, a emissora passou a transmitir em FM, na freqüência 101,9 $\mathrm{MHz}$. Foi a primeira emissora da cidade a efetivar a migração para o FM.

Rev.Cad.Comun. Santa Maria, v.22, n.1, art 5, p.111 de 120, jan/abr.2018 


\subsection{RÁDIO UNIVERSIDADE}

A emissora pertence à Universidade Federal de Santa Maria e é emissora de caráter educativa e não tem política editorial. Portanto, não há diretriz que orienta em relação a esta questão. Em entrevista realizada com a coordenação de jornalismo - na prática este tipo de notícia, não tem produção local, apenas em casos nacionais - pode ter alguma veiculação, já que a emissora retransmite o nacional informa da Rádio Nacional.

\section{ANÁLISE E DISCUSSÃo}

Em relação ao posicionamento da mídia santa-mariense, ela pode ser considerada homogênea, ou seja, a divulgação de suicídios acontece quando a pessoa que o cometeu tiver alguma repercussão pública, seja conhecida da opinião pública.

Apenas disto, uma emissora, a rádio Guarathan - ressaltou em sua resposta - que a não divulgação se dá em função da influência que este tipo de divulgação pode ter com pessoas que já tem uma pré-disposição ou estão em casos avançados de depressão.

No caso da Rádio Universidade não há divulgação local, foi a única emissora que foge da regra apontada pelas demais. Apenas casos nacionais podem ser transmitidos - porque há alguns programas em rede com a Rádio Nacional de Brasília.

Em outubro de 2015, foi realizado um evento na Universidade Federal de Santa Maria ${ }^{2}$ com a participação de profissionais da mídia para discutir o assunto. Durante a mesa redonda, foi debatida a importância que os jornalistas têm em informar sobre os indicadores e as melhores formas de prevenção. Os presentes relembraram também que o jornalista é um ser humano, e como tal, tem a sensibilidade de entender que a família, muitas vezes, prefere não falar sobre o assunto e não deve ser exposta.

A TV Pampa revelou que após a participação no evento, houve alteração no formato da divulgação, sendo acrescentado o número do CVV (Centro de Valorização da Vida) eentrevista com profissionais que poderiam auxiliar na prevenção.

O CFP (2013, p. 93) traz sua visão sobre esta influência da mídia na divulgação do suicídio: 
É certo, tal como recomenda a OMS em seus manuais, a necessidade de cuidado na divulgação dos acontecimentos, como é, na verdade, a divulgação de qualquer acontecimento. Contudo, se a mídia assumir um papel de fato informativo, desempenhará um papel importante na reflexão da sociedade acerca não só do suicídio propriamente dito, como também de suas múltiplas determinações e consequências. Vale lembrar que parte considerável da mídia responde a outros interesses, os da ideologização da realidade e de manutenção da sociedade tal como se encontra e, dessa maneira, discutir seriamente a questão do suicídio seria colocar em risco sua própria condição social.

Em 2000, através do programa de prevenção do suicídio, o SUPRE, a Organização Mundial da Saúde - OMS - lançou uma série de manuais contendo orientações relevantes sobre a prevenção do suicídio aos profissionais da mídia. Como destaca o manual (2000, p. 03):

A mídia desempenha um papel significativo na sociedade atual, ao proporcionar uma ampla gama de informações, através dos mais variados recursos. Influencia fortemente as atitudes, crenças e comportamentos da comunidade e ocupa um lugar central nas práticas políticas, econômicas e sociais. Devido a esta grande influência, os meios de comunicação podem também ter um papel ativo na prevenção do suicídio.

Desse modo, a preocupação gira em torno do cuidado em disseminar a informação de maneira apropriada. O documento enfatiza o impacto que a cobertura midiática pode ter nos suicídios, principalmente naqueles indivíduos mais vulneráveis.

Assim, aponta que dependendo da maneira como os meios de comunicação tratam e tornam públicos os casos de suicídio, estes podem efetivamente influenciar na ocorrência de novos suicídios, o que justifica o cuidado que se deve ter ao abordar o suicídio na pauta jornalística.

Este aspecto da imitação, também conhecido pelo "efeito de Werther", ou seja, o suicídio "por contágio" ou "copycat" é uma das primeiras relações conhecidas entre os meios de comunicação de massa e suicídio. O nome "efeito Werther" utilizado na literatura técnica para designar os suicídios que seguem um modelo, isto é, são imitativos teve a inspiração no romance de Goethe Die Leiden des Jungen Werthers, o qual acaba com o suicídio do seu protagonista. Este romance, após a sua primeira publicação em 1774, provocou uma onda de suicídios. A obra chegou a ser proibi-

Rev.Cad.Comun. Santa Maria, v.22, n.1, art 5, p.113 de 120, jan/abr.2018 
CADERNOS DE COMUNICAÇÃO

UNIVERSIDADE FEDERAL DE SANTA MARIA

da em determinadas regiões.

Segundo Coutinho (2010, p.65):

Na época, após ler a novela de Goethe, muitos jovens se mataram e em certos casos o faziam segurando um exemplar do livro. Desde então, estudos científicos demonstraram que a leitura ou o relato de casos de suicídios pode levar à identificação e à imitação, o que passou a ser conhecido como o "efeito Werther".

Dapieve (2007, p. 15) também apontou que "a expressão "efeito Werther" passou a ser usada sempre que um suicídio- sobretudo de artistasserve de inspiração para que outras pessoas se matem". O autor também cita o estudo realizado porDavid Phillips na década de 1970, ele se refere ao "fator Marilyn". Após a morte da atriz Marilyn Monroe por overdose de barbitúricos em 1962, constatou-se um aumento de $12 \%$ nos suicídios nos Estados Unidos, sendo que naquele momento, 303 pessoas além da taxa mensal norte americana decidiram-se, então, pela morte voluntária.

Neste sentido, tanto o "efeito Werther" quanto o "fator Marilyn" sugerem que os indivíduos mais vulneráveis com fatores de risco para uma potencial ideação e comportamento suicidas, incluindo passado histórico de ideação e/ou comportamento suicidas, podem ser influenciados e contagiados ao serem impactados com a divulgação de casos de suicídio pela mídia.

Segundo Coutinho (2010), o suicídio é universal ao longo de toda a história humana e está sob forte influência dos laços sociais, os quais o suicida se referencia ou dos quais é excluído. Para este autor a imitação e o contágio, são dois fenômenos que, assim como as notas suicidas, atestam a íntima relação que existe entre suicídio e laço social, se devem à veiculação de notícias de autoextermínio. O autor acrescenta que (2010, p.03):

$\mathrm{Na}$ imitação, um suicídio exerce um efeito modelador em suicídios subsequentes. No contágio, um suicídio facilita a ocorrência de novo autoextermínio, indiferentemente do direto ou indireto conhecimento do suicídio precedente. Reconhecida influência destes fenômenos no aumento das taxas de suicídio levou a Organização Mundial de Saúde a elaborar um guia para profissionais de mídia, para orientá-los quanto ao modo correto de noticiar um suicídio.

Rev.Cad.Comun. Santa Maria, v.22, n.1, art 5, p.114 de 120, jan/abr.2018 
Desse modo, o que os estudos apontam, é que existem evidências que algumas formas de noticiários e coberturas televisivas de suicídios associam-se a um excesso de suicídios estatisticamente significativo, tendo um impacto naqueles que já estão mais vulneráveis, com alguma predisposição ou algum grau de perturbação mental ou emocional.

Dapieve (2010), ao se referir a alguns estudos, ressalta que o papel dos meios impressos no processo de imitação teria peso maior que os dos meios eletrônicos, apontando que atelevisão teria uma probabilidade de $82 \%$ menor de deflagrá-lo que um jornal. O motivo para esta diferença seria atribuído ao fato de que na televisão, notícias sobre suicídio duram em média menos de 20 segundos e podem ser esquecidas ou até passar despercebidas. Por outro lado, as histórias divulgadas pela mídia impressa podem ser guardadas, lidas, relidas, postas nas paredes, enfim. Este fato se confirmou por encontrarem frequentemente ao lado dos corpos dos suicidas, cópias de notícias de outros casos de suicídios que haviam sido anteriormente veiculadas.

Porém, como aponta o manual para profissionais de mídia que orienta sobre a prevenção do suicídio: "O suicídio frequentemente tem apelo suficiente para ser noticiado, e a mídia tem o direito de mostrá-lo" e que "o relato de suicídios de uma maneira apropriada, acurada e cuidadosa, por meios de comunicação esclarecidos, pode prevenir perdas trágicas de vidas".

Resumidamente o manual da OMS (2000, p. 07) traz as seguintes sugestões:

O que fazer: - Trabalhar em conjunto com autoridades de saúde na apresentação dos fatos. - Referir-se ao suicídio como suicídio "consumado", não como suicídio "bem sucedido". • Apresentar somente dados relevantes, em páginas internas de veículos impressos. • Destacar as alternativas ao suicídio. • Fornecer informações sobre números de telefones e endereços de grupos de apoio e serviços onde se possa obter ajuda. • Mostrar indicadores de risco e sinais de alerta sobre comportamento suicida. O que NÃO fazer: • Não publicar fotografias do falecido ou cartas suicidas. - Não informar detalhes específicos do método utilizado. • Não fornecer explicações simplistas. • Não glorificar o suicídio ou fazer sensacionalismo sobre o caso. • Não usar estereótipos religiosos ou culturais. • Não atribuir culpas.

De acordo com a Associação Brasileira de Psiquiatria (2014) não se Rev.Cad.Comun. Santa Maria, v.22, n.1, art 5, p.115 de 120, jan/abr.2018 
pode prever exatamente quem vai se suicidar, mas podemos reconhecer alguns fatores de risco. Entre estesestariam a doença mental, muitas vezes não diagnosticada, frequentemente não tratada ou não tratada de forma adequada. Entre os transtornos psiquiátricos mais comuns estariam a depressão, transtorno bipolar, alcoolismo e abuso/dependência de outras drogas e transtornos de personalidade e esquizofrenia. Indivíduos com histórico de ideação suicida e que tentaram suicídio previamente tem de cinco a seis vezes mais chances de tentar suicídio novamente. Estão ainda entre os fatores de risco, os sentimentos de desesperança, desespero, desamparo e impulsividade.

Os estudos da Associação Brasileira de Psiquiatria - ABP - (2014) também apontam que o comportamento suicida entre jovens e adolescentes aumentou em todo mundo envolvendo motivações complexas, incluindo humor depressivo, abuso de substâncias, problemas emocionais, familiares, sociais, história familiar de transtorno psiquiátrico, rejeição familiar, negligência, além de abuso físico e sexual na infância.

Em relação ao gênero, os estudos da ABP (2014) colocam que os óbitos por suicídio são em torno de três vezes maiores entre homens do que entre mulheres, porém, as tentativas de suicídios são, em média, três vezes mais freqüentes entre as mulheres. Há evidências, também, que os conflitos em torno da identidade sexual causem um maior risco de comportamento suicida, o que aponta a necessidade de olharmos também para estas questões. As doenças clínicas não psiquiátricas, também estão entre os fatores de risco, os estudos evidenciaram que as taxas de suicídio são maiores entre pacientes com câncer, HIV, doenças neurológicas, doenças cardiovasculares, além de doenças reumatológicas, como o lúpus eritematoso sistêmico. Eventos adversos na infância e na adolescência como maus tratos, abuso físico e sexual, pais divorciados, transtorno psiquiátrico familiar, assim como a história familiar e genética da família estão entre os fatores de risco.

Entendemos que um fator importante acerca dos determinantes do suicídio refere-se ao papel da mídia e os estudos sugerem que existem fatores de risco e grupos de pessoas suscetíveis ao suicídio, em decorrência do efeito da mídia. Desse modo, tratar deste tema numa pauta jornalística é algo complexo e implica em reflexões específicas que levem em consideração todos os determinantes que envolvem a questão do suicídio e que implica em ética e responsabilidade.

Rev.Cad.Comun. Santa Maria, v.22, n.1, art 5, p.116 de 120, jan/abr.2018 
Segundo consta nas orientações sobre como abordar o suicídio na imprensa da $\operatorname{ABP}$ (2009, p.20)

\begin{abstract}
Quando o suicídio for notícia (e esse critério varia entre os órgãos de imprensa) sugere-se reportagem discreta, cuidadosa com parentes e amigos enlutados, sem detalhismo exagerado do método suicida, notadamente quando o falecido era celebridade, ou pessoa muito estimada localmente. Acredita-se que carregar a reportagem de tensão, por meio de descrições e imagens de amigos e de familiares impactados, acabe por encorajar algumas pessoas mais vulneráveis a tomarem o suicídio como forma de chamar a atenção ou de retaliação com outros.
\end{abstract}

Mesmo diante de recomendações e sugestões da OMS, da Associação Brasileira de Psiquiatria entre outros órgãos que trabalham em prol da orientação e prevenção em relação ao suicídio, cada veículo de comunicação segue seus próprios critérios de divulgação e noticiabilidade quanto ao suicídio.

Ou seja, se o objetivo for, além de levar o fato até o receptor, assimilar também algo a mais sobre como prevenir, ajudar - esta divulgação é vista como positiva.

\title{
5 EM BUSCA DE APONTAMENTOS FINAIS
}

A conscientização deve ser um trabalho permanente e é importante que profissionais de saúde se atrelem à mídia e criem campanhas de prevenção durante o ano todo.

O jornalismo utiliza como premissa do que deve ser notícia - o interesse público, por isto - muitos veículos de comunicação o fazem quando o autor for uma pessoa pública, na divulgação de um suicídio.

Na mídia santa-mariense a divulgação de suicídios acontece quando a pessoa que o cometeu tiver alguma repercussão pública, seja conhecida da opinião pública.

Já foi realizado um evento com representantes dos profissionais na cidade em 2015 e há o entendimento da responsabilidade dos meios de comunicação em relação ao que pode ser considerado um gatilho - para potencializar mais casos, por isto a restrição parcial na divulgação. Por outro lado, nota-se que o evento trouxe também uma contribuição para o formato da divulgação, o foco, sendo que as entrevistas com profissionais

Rev.Cad.Comun. Santa Maria, v.22, n.1, art 5, p.117 de 120, jan/abr.2018 
da saúde e de telefone de apoio são divulgados. Este ponto de vista também corrobora com a do Conselho Federal de Psicologia - conforme seu trabalho divulgado em 2013 sobre os desafios do Suicídio para a Psicologia e com os autores deste trabalho, amparados com a análise feita da política editorial dos veículos de comunicação de Santa Maria pesquisados.

Comparando as diferentes mídias existentes e alguns estudos apontados no trabalho, a mídia impressa é a que representa o maior perigo por ser possível guardar as edições para ver em momentos futuros, por isto o cuidado deste veículo deve ser redobrado, pois pode potencializar atos suicidas. 


\section{REFERÊNCIAS}

ASSOCIAÇÃO BRASILEIRA DE PSIQUIATRIA -ABP. (2009). Comportamento suicida: Conhecer para prevenir. Dirigido para profissionais de imprensa. Disponível em: <goo. gl/wfffYy>. Acesso em: 14 jun. 2017.

ANJ. Associação Nacional de Jornais. Número de jornais brasileiros. Disponível em: <goo.gl/aS2RCp>. Acesso em: 22 mar. 2017.

BRASIL. Ministério das Comunicações. Ministério das Comunicações atualiza lista com dados de emissoras. 2014. Disponível em: <goo.gl/oUaXWa>. Acesso em: 23 fev. 2017.

CONSELHO FEDERAL DE PSICOLOGIA. O Suicídio e os Desafios para a Psicologia. Conselho Federal de Psicologia. - Brasília: CFP, 2013.

COUTINHO, A.H.S.A. (2001) Suicídio: agreSIvidade. Reverso, n.48, p.76-87, Belo Horizonte, 2001.

DAPIEVE, Arthur. Morreu na Contramão: o Suicídio como notícia. Rio de Janeiro. Jorge Zahar Ed, 2007.

DUARTE, Jorge. (2006). Comunicação Pública. Disponível em: <goo.gl/xn4bh>. Acesso em: 23 fev. 2017

GRUPO RBS. Guia de ética e autorregulamentação jornalística. Grupo RBS. - Porto Alegre: RBS Publicações, 2011.

RIGO, Soraya Carvalho. Suicídio: uma questão de saúde pública e um desafio para a psicologia clínica. Parte 1. Capítulo 3. In: O Suicídio e os Desafios para a Psicologia. Conselho Federal de Psicologia. - Brasília: CFP, 2013.

ORGANIZAÇÃO MUNDIAL DA SAÚDE. Prevenção do suicídio: um manual para profissionais da mídia. Genebra, 2000. Disponível em: <goo.gl/6M86an>. Acesso em: 14 jun. 2017.

WERLANG, Bianca. Suicídio: uma questão de saúde pública e um desafio para a psicologia clínica. Parte 1. Capítulo 2. In: O Suicídio e os Desafios para a Psicologia. Conselho Federal de Psicologia. - Brasília: CFP, 2013. 


\section{Valmor Rhoden}

Pós-Doutorando em Educação - UFSM ( 2017). Doutor em Comunicação - PUCRS ( 2013). Professor adjunto do curso de Relações Públicas da Unipampa - Campus São Borja - RS. E-mail:vrhoden6@gmail.com

\section{Juliana Lima Moreira Rhoden}

Doutoranda em Educação. Psicóloga. Professora Adjunta da Universidade Federal do Pampa - Campus São Borja E-mail: juli.rhoden@gmail.com

\section{Douglas Moreira Dornelles}

Acadêmico do Curso de Psicologia da UNIFRA.

RECEBIDO EM: 15/08/2017

ACEITO EM: 15/10/2017 